\title{
Interleukin-1 $\beta$ Mediates the Extra-Intestinal Thrombosis Associated with Experimental Colitis
}

\author{
Hideo Yoshida, ${ }^{*}$ Janice Russell, ${ }^{\dagger}$ \\ Elena Y. Senchenkova, ${ }^{\dagger}$ \\ Lidiana D. Almeida Paula, $^{\dagger}$ and D. Neil Granger ${ }^{\dagger}$ \\ From the Eiju General Hospital,* Tokyo, Japan; and the \\ Department of Molecular and Cellular Physiology, ${ }^{\dagger}$ Louisiana \\ State University Health Sciences Center, Shreveport, Louisiana
}

Inflammatory bowel diseases (IBDs) are associated with an increased risk for thromboembolism, which is often manifested as deep vein thrombosis or pulmonary embolism, at extra-intestinal sites. Although some of the cytokines that contribute to IBD pathogenesis are also known to alter the coagulation pathway, it remains unclear whether these mediators also contribute to the extra-intestinal thrombosis often associated with IBD. The objective of this study is to evaluate the role of interleukin (IL)-1 $\beta$ in enhanced extra-intestinal thrombosis observed in mice with dextran sodium sulfate (DSS)-induced colitis. IL-1 $\beta$ concentrations were measured in plasma, colon, and skeletal muscle of wild-type (WT) control and colitic mice. Microvascular thrombosis was induced in cremaster muscle microvessels by using a light/dye injury model. The effects of exogenous IL-1 $\beta$ on thrombus formation were determined in control WT mice. DSS-induced thrombogenesis was evaluated in WT mice treated with an $\mathrm{IL}-1 \beta$ antibody and in $\mathrm{IL}-1$ receptor-deficient (IL-1r ${ }^{-/-}$) mice. DSS-induced colonic inflammation in WT mice was associated with enhanced thrombus formation in arterioles. IL-1 $\beta$ concentrations were elevated in inflamed colon and skeletal muscle. Exogenous IL-1 $\beta$ enhanced thrombosis in control mice in a dose-dependent manner. DSS colitic mice treated with the IL-1 $\beta$ antibody as well as IL$1 r^{-/-}$mice exhibited significantly blunted thrombogenic responses. These findings implicate IL-1 $\beta$ as a mediator of enhanced microvascular thromboses that occur in extra-intestinal tissues during colonic inflammation. (Am J Pathol 2010, 177:2774-2781; DOI: 10.2353/ajpath.2010.100205)

Inflammatory bowel diseases (IBD) are associated with an increased risk for thromboembolism, which is often manifested as deep vein thrombosis or pulmonary embolism. The prothombogenic state that accompanies human IBD is believed to arise from an imbalance between pro- and anti-coagulant factors. ${ }^{1,2}$ A similar procoagulant/prothrombogenic phenotype is evident in animal models of experimental colitis, which exhibit elevated blood levels of thrombin-antithrombin complexes, reduced protein $\mathrm{C}$, and decreased antithrombin III. $^{3-5}$ These changes in coagulant-anticoagulant factors are accompanied by enhanced thrombus formation in microvessels of organs distant to the colon, such as skeletal muscle. ${ }^{3,6,7}$ Although the contributions of different pro(tissue factor, thrombin) and anti- (activated protein C) coagulants to colitis-enhanced extra-intestinal thrombosis have been evaluated, ,3,6,7 the chemical and/or cellular signal produced by the inflamed colon that promotes thrombosis at distant sites remain undefined.

A variety of cytokines have been implicated in the pathogenesis of IBD. Interleukin-1beta (IL-1 $\beta$ ) has received considerable attention as a potential mediator of inflammatory cell infiltration and mucosal barrier disruption that accompanies gut inflammation. ${ }^{8} \mathrm{IL}-1 \beta$ also appears to promote inflammation by stimulating the production of other cytokines (eg, IL-6) and chemokines (eg, CXCL1, CXCL8, IL-8). ${ }^{9-11}$ A less studied characteristic of $\mathrm{IL}-1 \beta$ is its procoagulant actions. The cytokine is known to induce the expression of tissue factor while down-regulating the protein $\mathrm{C}$ pathway, which are features of the prothrombogenic response elicited in the microvasculature of dextran sodium sulfate (DSS) colitic mice. ${ }^{3,4,6}$ These properties of IL-1 $\beta$, coupled to its ability to stimulate the production of other powerful procoagulant cytokines like IL- $6,{ }^{12}$ suggest that IL- $1 \beta$ is a viable candidate mediator of the distant organ thrombogenesis that accompanies colonic inflammation.

The overall objective of this study was to determine whether IL-1 $\beta$ contributes to the enhanced extra-intesti-

Supported by a grant from the National Institutes of Diabetes, Digestive and Kidney Diseases (P01 DK43785-18).

Accepted for publication August 26, 2010.

Address reprint requests to D. Neil Granger, Ph.D., Department of Molecular and Cellular Physiology, Louisiana State University Health Sciences Center, 1501 Kings Highway, PO Box 33932, Shreveport, Louisiana 71130-3932. E-mail: dgrang@|suhsc.edu. 
nal thrombosis in experimental colitis. To achieve this objective, we evaluated (1) IL-1 $\beta$ levels in colon, skeletal muscle, and plasma of control and DSS colitic mice by using a cytometric bead array; (2) the thrombogenic response of cremaster muscle arterioles to light/dye-induced endothelial injury after administration of different doses of recombinant murine IL-1 $\beta$; (3) thrombus formation in wild-type (WT) colitic mice receiving a polyclonal anti-IL-1 $\beta$ antibody (Ab), (4) thrombus formation in IL-1 receptor deficient mice with DSS colitis, and (5) in mice deficient in myeloid differentiation protein-88 (MyD88), a cytoplasmic adaptor molecule that enables the IL-1 receptor to activate nuclear factor kappa B and elicit the production of different cytokines and chemokines. ${ }^{11}$ Our findings suggest that IL-1 $\beta$ mediates the enhanced extraintestinal thrombosis associated with colonic inflammation via a MyD88-independent signaling mechanism.

\section{Materials and Methods}

\section{Animals}

A total of 98 male C57BL/6J mice, including $10 \mathrm{IL}-1$ receptor-1 deficient (IL-1r ${ }^{-1-}$ ) mice, seven MyD88 deficient $\left({\mathrm{MyD} 88^{-/-}}^{-}\right)$mice, and five recombinase activating gene-1 (RAG-1 $1^{-I-}$ ) mice were purchased from Jackson Laboratory Bar Harbor, ME for this study. All mice were housed under specific pathogen-free conditions in standard cages and fed standard laboratory chow and water until the desired age (6 to 8 weeks). All animal procedures were reviewed and approved by the Institutional Animal Care and Use Committee of Louisiana State University Health Sciences Center and were performed according to the criteria outlined by the National Institutes of Health.

\section{Experimental Colitis Model}

Colitis was induced, as previously described, ${ }^{13}$ by feeding mice 3\% (w/v) DSS (40,000 molecular weight; MP Biomedicals, Solon, $\mathrm{OH}$ ) dissolved in filter-purified drinking water. The first day of DSS feeding was defined as day 0 , and the mice were maintained on the DSS until day 6. The $3 \%$ DSS regimen, unlike higher DSS doses, is not associated with mortality. Control mice received filtered water alone (without DSS).

In a separate group of experiments, the light/dye-induced microvascular thrombosis responses were compared between WT mice with DSS-induced colitis and mice with colitis induced by the adoptive transfer (i.p.) of $\mathrm{CD}^{+}{ }^{-}$T-lymphocytes $\left(1 \times 10^{6}\right.$ cells $)$ obtained from IL$10^{-/-}$mice into $\mathrm{RAG}^{-/-}$recipients. IL-10 ${ }^{-/-}$splenocytes were enriched for $\mathrm{CD}^{+}{ }^{+} \mathrm{T}$ cells $(>85 \%)$ by using a commercially available negative selection kit specifically for $\mathrm{CD}^{+}{ }^{+} \mathrm{T}$ cells (Dynal, Carlsbad, CA), as previously described. ${ }^{14}$ The T-cell transfer model produces murine colitis at 8 weeks following adoptive transfer of the IL$10^{-1-} \mathrm{CD} 4^{+} \mathrm{T}$ cells.

\section{Assessment of Colitis Progression}

Body weights, fecal status, presence of occult blood in the stools, and peri-anal bleeding were observed and recorded every day while the mice received DSS. Occult blood was detected by using guaiac paper (ColoScreen; Helena Laboratories, Beaumont, TX). ${ }^{13}$ Disease activity index (DAI), a measure of disease severity ranging between 0 and 4, was calculated from data collected on stool consistency, presence or absence of fecal blood, and weight loss, as previously described. ${ }^{13}$ The DAI was measured daily to confirm that DSS treatment resulted in clinical responses that are consistent with colitic disease activity.

\section{Cytokine (IL-1ß) Concentration}

IL-1 $\beta$ levels in plasma, colon, and skeletal muscle (quadriceps) were measured by using a cytometric bead array. To obtain the plasma samples, the right carotid artery was cannulated with a phosphatidylethanolamine 10 tube (BD, Flanklin Lakes, NJ). A blood sample was withdrawn and collected in an Eppendorf tube, which was then centrifuged at $5000 \mathrm{rpm} \times 10$ minutes to separate the plasma. Tissue samples were promptly mixed with PBS containing a protease inhibitor (Sigma Chemicals, St. Louis, MO) and thoroughly homogenized. The homogenate was centrifuged at $10,000 \mathrm{rpm} \times 5$ minutes to separate the supernatant. IL-1 $\beta$ concentrations in the supernatants and plasma samples were measured with the cytometric bead array as per the manufacturer's instruction (BD Biosciences, San Jose, CA). The detection limit of the cytometric bead array for mouse $\mathrm{IL}-1 \beta$ is $10 \mathrm{pg} / \mathrm{ml}$.

\section{Surgical Preparation for Intravital Microscopy}

On day 6 of DSS (colitis) or water (control) treatment, mice were anesthetized by using $50 \mathrm{mg} / \mathrm{kg}$ body wt. (i.p.) pentobarbital, with supplemental doses of $12.5 \mathrm{mg} / \mathrm{kg}$, given as needed. The right internal jugular vein was cannulated for intravenous administration of fluorescein isothiocyanate (FITC) dextran, and the right carotid artery was cannulated for measurement of systemic blood pressure. Body temperature was maintained at $36.5^{\circ} \mathrm{C}$ to $37.5^{\circ} \mathrm{C}$ during the entire experiment with a homeothermic blanket and monitored with a rectal temperature probe. An incision was made in the scrotal skin to expose the left cremaster muscle. A lengthwise incision was made on the surface of the cremaster muscle. The testicle and epididymis were separated from the muscle. The muscle was spread out on the pedestal and the edges of the muscle were moderately extended with sutured threads. ${ }^{15}$ The surface of the exposed cremaster muscle was suffused continuously with bicarbonate-buffered saline, with a pH 7.35 to 7.45 .

\section{Microscopic Observation}

The microvasculature was observed by using an upright microscope (BX51WI; Olympus, Tokyo, Japan) with a 40X water immersion objective lens (LUMPlanFI/IR 40X/ 
$0.80 \mathrm{w}$, Japan). The light and fluorescent microscopic images were projected onto a monitor (TRINITRON PVM2030; Sony, Tokyo, Japan) through a color video camera (Hitachi VK-C150; Hitachi, Tokyo, Japan) or a chargecoupled device video camera (Hamamatsu XC-77; Hamamatsu, Tokyo, Japan), respectively. The images were recorded by using a DVD recorder (JVC SR-MV50, $\mathrm{NJ}$ ). A video timer (Panasonic Time-Date Generator WJ810; Panasonic, Tokyo, Japan) was connected to the monitor to record time and date. The diameters of the cremaster vessels were measured by video analysis software (ImageJ 1.37v; NIH, Public Domain software) on a personal computer (G4 Macintosh; Apple, Cupertino, $\mathrm{CA})$. Red blood cell velocity $\left(\mathrm{V}_{\mathrm{RBC}}\right)$ in the microvessels was measured by using an optical Doppler velocimeter (Microcirculation Research Institute, Texas A\&M University, College Station, TX). Blood flow was calculated from the product of mean red blood cell velocity $\left(V_{\text {mean }}=\right.$ $\left.V_{\mathrm{RBC}} / 1.6\right)$ and cross-sectional area, assuming cylindrical geometry. Wall shear rate was calculated based on the Newtonian definition: wall shear rate $=8\left(V_{\text {mean }} / D_{V}\right)$.

\section{Video Analysis}

In each mouse, four to five venular segments with a diameter of 35 to $50 \mu \mathrm{m}$, at least $100 \mu \mathrm{m}$ in length, and a wall shear rate $\geq 500$ per second were randomly selected for study in the cremaster muscle. Leukocytes were classified according to quality or duration of their interaction with the venular wall as either free-flowing, rolling, or adherent. ${ }^{16}$ Rolling leukocytes were defined as cells crossing the $100 \mu \mathrm{m}$ venular segment at a velocity that is significantly lower than the center line blood flow. Adherent leukocytes were defined as remaining stationary for $\geq 30$ seconds. ${ }^{17}$ The number of rolling or adherent leukocytes were expressed as number of cells per minute per millimeter of vessel area, calculated from diameter and length, assuming cylindrical vessel shape.

\section{Light/Dye-Induced Thrombosis}

Second or third-order venules and arterioles (one to three per mouse), meeting the characteristics described above, were randomly selected in each cremaster muscle to study thrombus formation. Then, $10 \mathrm{ml} / \mathrm{kg}$ of $5 \%$ FITC-dextran (150,000 MW; Sigma Chemicals) was slowly injected into the intravenous cannula and allowed to circulate for 10 minutes. Photoactivation of FITC-dextran (excitation: $495 \mathrm{~nm}$; emission: $519 \mathrm{~nm}$ ) within the microvessels was achieved by epi-illumination using a 175-W xenon lamp (Lambda LS, Sutter, CA) and a fluorescein filter cube (HQ-FITC, Chroma Technology Company, Rockingham, VT). The excitation power density was measured daily (ILT 1700 Radiometer, SED033 detector; International Light, Peabody, MA) and maintained within $1 \%$ of $0.74 \mathrm{~W} / \mathrm{cm}^{2}$, as previously described. ${ }^{18,19}$ Epi-illumination was continuously applied to the vessels, and thrombus formation was quantified by determining (1) the time of onset of platelet deposition/aggregation within the microvessel (onset time), and (2) the time re- quired for complete flow cessation for $\geq 60$ seconds (cessation time). Epi-illumination was discontinued once blood flow ceased in the vessel under study. The results of each vessel type (venules, arterioles) were averaged between 1 and 3 thrombi produced in each mouse.

\section{Experimental Protocols: In Vivo Thrombosis}

The light/dye method was used to monitor thrombus formation in the following experimental groups: (1) control WT mice receiving an intrascrotal injection of $0.2 \mathrm{ml}$ of saline at 4 hours before vessel photoactivation; (2) WT mice receiving an intrascrotal injection of recombinant mouse IL-1 $\beta$ (Calbiochem, La Jolla, CA) at a concentration of either $0.2,1.0$, or $5.0 \mu \mathrm{g} / \mathrm{kg}$ (dissolved in $0.2 \mathrm{ml}$ of normal saline) at 4 hours before photoactivation; (3) DSStreated WT mice receiving (i.p., 24 hours before photoactivation) $100 \mu \mathrm{g} /$ mouse of a polyclonal anti-mouse IL- $1 \beta$ antibody (goat IgG; R\&D Systems, Minneapolis, $\mathrm{MN}$ ) dissolved $0.2 \mathrm{ml}$ of normal saline; (4) DSS-treated WT mice receiving (i.p., 24 hours before photoactivation) $100 \mu \mathrm{g} /$ mouse of a control antibody (goat lgG; R\&D Systems) dissolved $0.2 \mathrm{ml}$ of normal saline; (5) watertreated interleukin-1 receptor deficient $\left(\mathrm{IL}-1 \mathrm{r}^{-/-}\right)$mice; (6) DSS-treated $\mathrm{IL}-1 \mathrm{r}^{-1-}$ mice; and (7) DSS-treated MyD88 ${ }^{-1-}$ mice. A separate group $(n=3)$ of mice were rendered neutropenic by intraperitoneal injection (150 $\mu \mathrm{g}$ ) of anti-neutrophil serum (RB6-8C5, rat anti-mouse Ly-6G; eBioscience, San Diego, CA) 24 hours before the induction of light/dye injury. Anti-neutrophil treatment yielded a $93.7 \pm 3.6 \%$ reduction in blood neutrophil count. In another group of control $(n=5)$ and colitic $(n=$ 5) mice, we quantified the rolling and firm adherence of leukocytes in cremaster venules. Additional water $(n=5)$ or DSS $(n=5)$ fed mice were used to collect colon, skeletal muscle, and plasma samples for determination of $\mathrm{IL}-1 \beta$ concentration.

\section{In Vitro Platelet Aggregation}

Freshly collected platelet rich plasma from donor mice was used to monitor platelet aggregation velocity following agonist exposure by using a Laser Particle Analyzer (Lumex Ltd., St. Petersburg, Russia). Initially, the $\mathrm{EC}_{50}$ value (concentration required to achieve half-maximum velocity) for aggregation velocity of wild type platelets in response to thrombin $(0.25 ; 0.5 ; 1$; and $4 \mathrm{U} / \mathrm{ml})$ was determined as previously described. ${ }^{20}$ Thrombin was chosen as the platelet agonist because previous work has implicated this pro-coagulant as a critical mediator of DSS colitis-enhanced microvascular thrombosis. ${ }^{7}$ This method yielded an $\mathrm{EC}_{50}$ of $0.63 \mathrm{U} / \mathrm{ml}$, which was subsequently used to compare the aggregation velocity of platelets derived from the following experimental groups: (1) WT mice $(n=6)$ placed on tap water (WT-Control); (2) WT mice $(n=6)$ placed on 3\% DSS (WT-DSS); (3) WT-DSS mice $(n=5)$ treated with the IL- $1 \beta$ antibody (as described above); and (4) IL-1 receptor-deficient mice $(n=5)$ treated with DSS (IL-1r $\left.{ }^{-1-}-\mathrm{DSS}\right)$. 


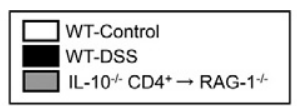

Venules
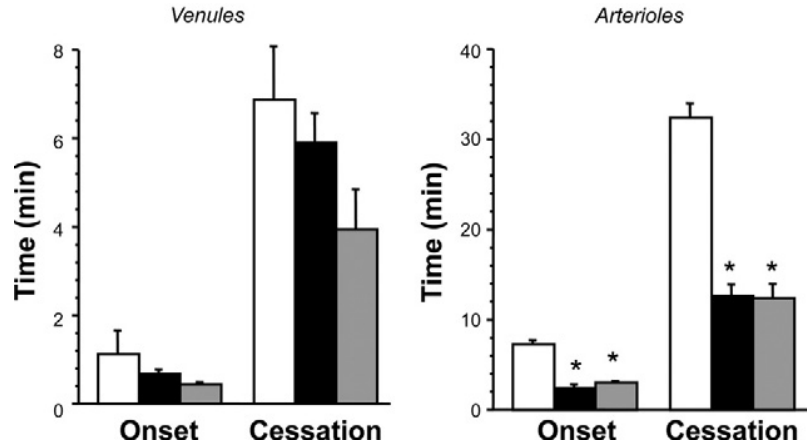

Figure 1. Effects of colonic inflammation induced by either DSS or the transfer of $\mathrm{IL}-10^{-/-} \mathrm{CD}^{+}$T cells into immunodeficient $\mathrm{RAG}-1^{-/-}$mice on light/dye-induced thrombus formation in cremaster muscle arterioles and venules; $n=7$ in the WT-control and WT-DSS groups, and $n=5$ in the IL- $10^{-/-} \mathrm{CD}^{+} \rightarrow$ RAG $-1^{-/-}$group. ${ }^{*} P<0.05$ versus control WT.

\section{Statistics}

Data were analyzed by using standard statistical analysis, ie, one-way analysis of variance and Fisher's post hoc test. All values are reported as means \pm SE from four to seven mice.

\section{Results}

All mice placed on 3\% DSS exhibited a significantly increased DAI without mortality. There was no statistical difference in DAI on day 6 of DSS treatment between any of experimental groups.

Figure 1 shows the changes in time of onset of thrombosis and the time to flow cessation induced by light/dye injury in cremaster muscle arterioles and venules of WT control and DSS-treated (colitic) mice. As previously reported, 3,6,19 the time required for the initiation (onset) and termination (cessation) of thrombus formation is much longer in arterioles than in venules. Although no differences were noted in either the time of onset or time to flow cessation between venules of control and colitic mice, both variables were significantly reduced (consistent with accelerated thrombosis) in cremaster arterioles of colitic mice. The accelerated thrombus formation in arterioles of DSS colitic mice is consistent with previous reports. ${ }^{3,6}$ The figure also illustrates that a similar pattern of enhanced thrombosis in cremaster arterioles is evidenced in an immune model of colitis that results from the transfer of $\mathrm{CD}^{+}{ }^{+} \mathrm{T}$-cells from IL-10 ${ }^{-/-}$mice into immunodeficient $\mathrm{RAG}-1^{-1-}$ mice. These results indicate that the enhanced extra-intestinal thrombosis observed during colonic inflammation is not unique to the DSS model.

Figure 2 summarizes the changes detected in the number of rolling and firmly adherent leukocytes in venules of cremaster muscle in mice with DSS-induced colonic inflammation. Although no significant differences in wall shear rate were noted between venules of control $\left(724.1 \pm 68.5\right.$ seconds $\left.^{-1}\right)$ and colitic (714.82 \pm 78.9 seconds ${ }^{-1}$ ) mice, a marked increase in the number of
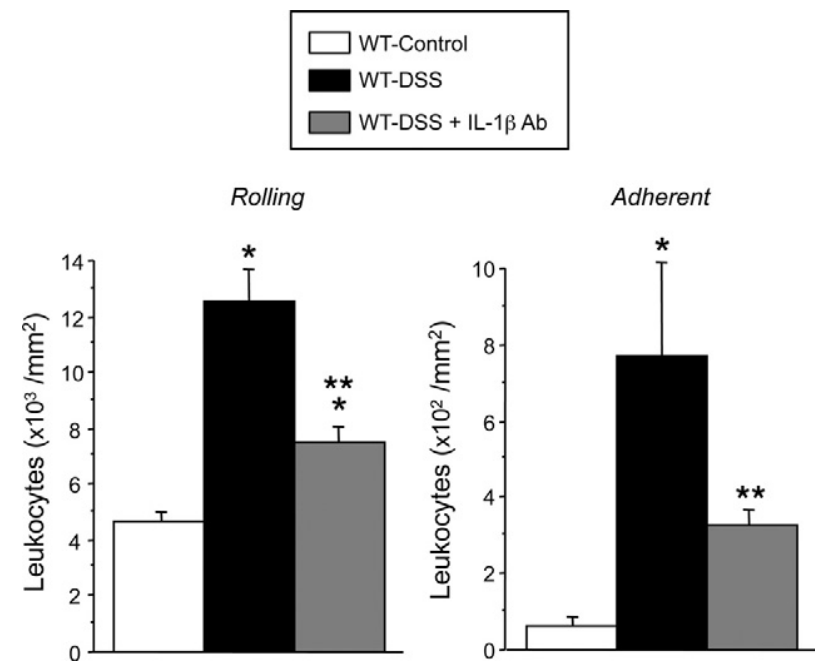

Figure 2. Rolling and adherent leukocytes in cremaster muscle venules of control $(n=5)$, DSS-treated WT $(n=7)$, and anti- IL- $1 \beta$ antibody + DSS-treated WT $(n=5) .{ }^{*} P<0.01$ versus control WT; ${ }^{* *} P<0.01$ versus colitic WT mice.

rolling and adherent leukocytes was detected in venules of colitic mice. IL-1 $\beta$ immunoblockade significantly reduced the total number of both rolling and adherent leukocytes increased by DSS colitis. These results suggest that the cremaster microcirculation assumes an inflammatory phenotype during DSS colitis and that IL-1 $\beta$ contributes to this response.

Mice rendered neutropenic with anti-neutrophil serum were studied to determine whether the leukocyte recruitment noted in the cremaster muscle of DSS-treated mice contributes to the enhanced thrombosis response. A comparison of the time of onset $(2.0 \pm 0.5$ minutes versus $3.3 \pm 0.7$ minutes; untreated versus anti-neutrophil serum-treated) and the time to flow cessation (15.4 \pm 1.6 minutes versus $16.2 \pm 0.9$ minutes) between DSS and neutropenic DSS mice revealed no statistically significant differences in the thrombosis responses to light/dye injury, suggesting that neutrophils do not mediate the extra-intestinal thrombosis observed in DSS mice.

Figure 3 summarizes the $\mathrm{IL}-1 \beta$ concentrations detected in colonic and skeletal muscle tissue of control and DSS colitic mice. The inflamed colon exhibited a large ( $\sim 18$-fold) increase in IL-1 $\beta$ concentration, compared with normal colon. Although plasma IL-1 $\beta$ tended to be higher in DSS colitic mice compared with controls $(2.06 \pm 1.49$ versus $0.56 \pm 0.39 \mathrm{pg} / \mathrm{ml})$, this difference did not reach statistical significance $(P=0.31)$. Although $\mathrm{IL}-1 \beta$ concentration measured in skeletal muscle of control mice was largely undetectable $(1.34 \pm 0.67 \mathrm{pg} / \mathrm{ml})$, a significantly elevated concentration (21.32 $\pm 5.5 \mathrm{pg} / \mathrm{g}$ ) was detected in skeletal muscle tissue of DSS colitic mice.

Figure 4A compares the thrombosis responses to light/ dye injury in arterioles of cremaster muscle between control WT mice on normal drinking water to a similar group of mice receiving an intrascrotal injection of saline. These findings demonstrate that the intrascrotal injection protocol per se does not alter the thrombosis responses to light/dye injury. Figure 4B compares the thrombosis responses to light/dye injury in arterioles of control WT, 


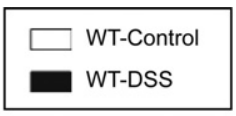

Colon

Skeletal muscle
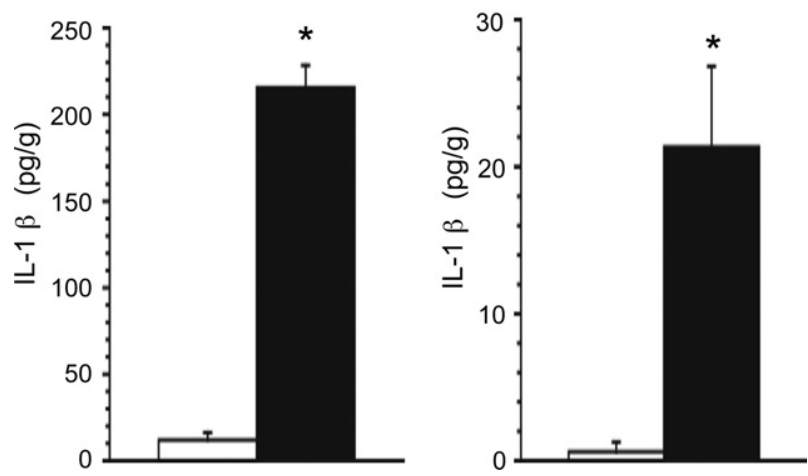

Figure 3. IL- $1 \beta$ cytokine concentrations in colon and skeletal muscle (quadriceps) of control $(n=5)$ and DSS-treated WT mice $(n=5) .{ }^{*} P<0.01$ versus control WT.

DSS-treated WT, and control WT receiving an intrascrotal injection of either $0.2,1.0$, or $5.0 \mu \mathrm{g} / \mathrm{kg}$ of IL-1 $\beta$. Although the lowest dose $(0.2 \mu \mathrm{g} / \mathrm{kg})$ of $\mathrm{IL}-1 \beta$ did not alter thrombosis, the higher doses significantly accelerated thrombosis, as manifested by a reduction in both the time of onset and time to flow cessation. However, the highest dose $(5.0 \mu \mathrm{g} / \mathrm{kg})$ of $\mathrm{IL}-1 \beta$ did not produce a greater response than noted with $1.0 \mu \mathrm{g} / \mathrm{kg}$. Even with the higher doses of IL-1 $\beta$, the magnitude of the prothrombotic effect on the time to flow cessation did not equal that elicited by DSS treatment.

Figure 5 compares the thrombosis responses to light/ dye injury in cremaster arterioles of control mice, colitic mice, and colitic mice treated with an anti-IL-1 $\beta$ antibody. The mice receiving the $\mathrm{IL}-1 \beta$ blocking $\mathrm{Ab}$ exhibited $\mathrm{a}$ significant attenuation of the colitis enhanced thrombosis response, as reflected by the increases in both the time
A

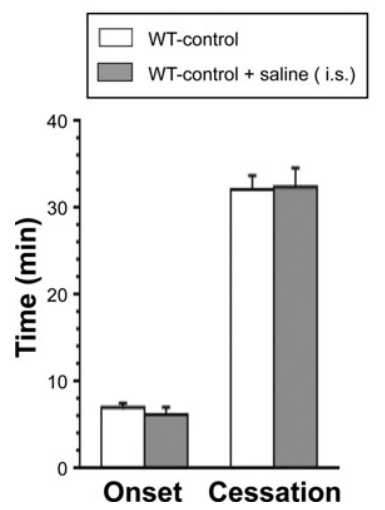

B
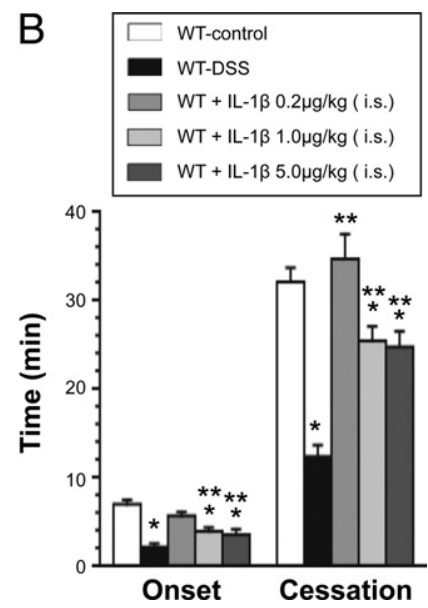

Figure 4. A: Effects of intrascrotal injection of $0.20 \mathrm{ml}$ normal saline on light/dye-induced thrombus formation (4 hours after injection) in cremaster muscle arterioles of control mice $(n=5)$. B: Effects of intrascrotal administration of $\mathrm{IL}-1 \beta(0.2,1.0$, or $5.0 \mu \mathrm{g} / \mathrm{kg})$ dissolved in $0.2 \mathrm{ml}$ normal saline on thrombus formation ( 4 hours after injection) in cremaster muscle arterioles. The data are compared with the responses in DSS colitic mice. Control W'T $(n=7)$, DSS-treated WT $(n=7)$, all IL-1 $\beta$ administration groups $(n=5)$. ${ }^{*} P<0.05$ versus control WT; ${ }^{* *} P<0.05$ versus colitic WT.

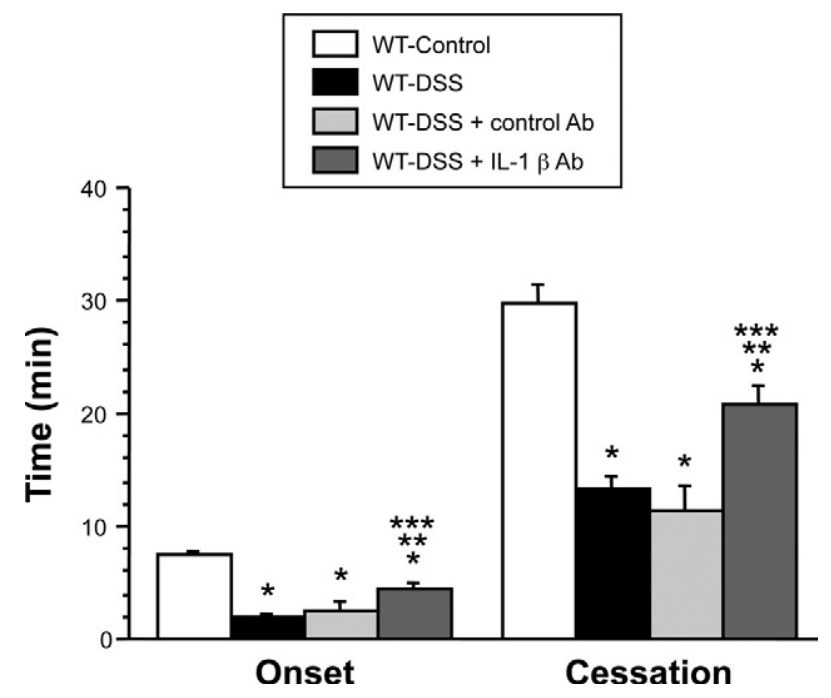

Figure 5. Effects of IL-1 $\beta$ immunoneutralization (IL-1 $\beta \mathrm{Ab}$ ) on DSS colitisinduced thrombus formation in cremaster muscle arterioles (WT-DSS + IL-1 $\beta$ Ab, $n=6)$. WT controls $(n=11)$, WT-DSS $(n=11)$, and WT-DSS + control $\mathrm{Ab}(n=4) .{ }^{*} P<0.05$ versus control WT; ${ }^{*} P<0.05$ versus colitic WT; ${ }^{\dagger} P<$ 0.05 versus colitic WT + control Ab.

of onset of the thrombus and the time to flow cessation. The control Ab (goat lgG) did not alter the colitis-enhanced thrombosis response after light/dye injury. These data suggest that IL-1 $\beta$ contributes to the accelerated thrombosis induced by DSS colitis.

Figure 6 illustrates the different thrombosis responses noted between WT colitic mice and IL-1r ${ }^{-1-}$ mice with DSS colitis. IL-1r ${ }^{-1-}$ mice placed on normal water did not exhibit thrombosis responses that differed from control WT mice. However, DSS-treated IL-1 $\mathrm{r}^{-/-}$mice exhibited significantly blunted thrombosis responses compared with their wild type counterparts. The protection afforded
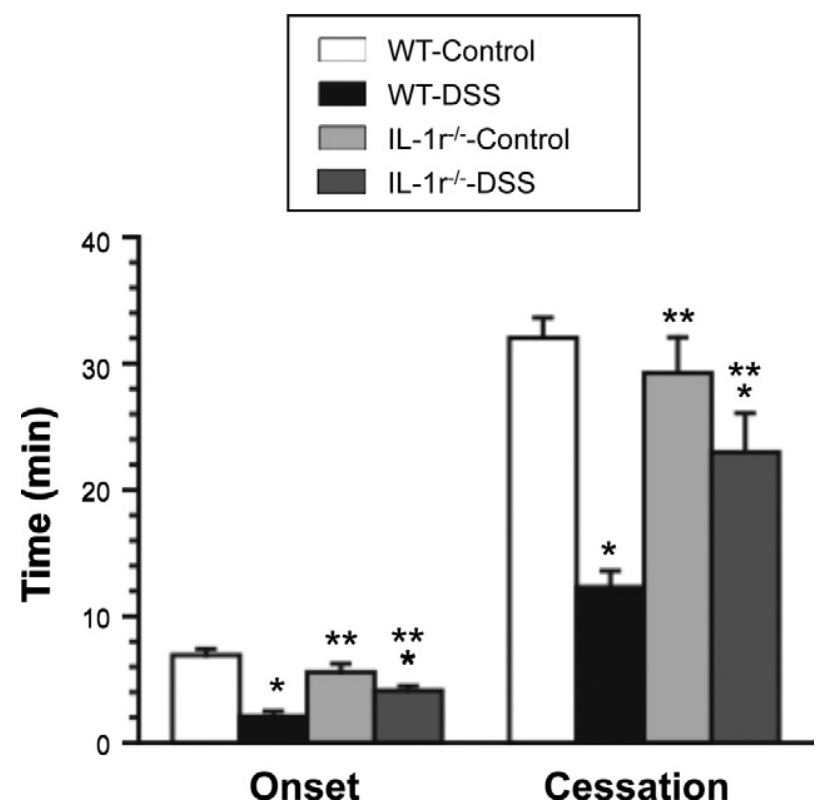

Figure 6. Effects of IL-1 receptor deficiency on thrombus formation in cremaster arterioles of DSS colitic mice. Control WT $(n=7)$, colitic WT ( $n=$ 7), non-colitic IL- $1 \mathrm{r}^{-/-}$mice $(n=5)$, and colitic IL-1R KO mice $(n=5)$. ${ }^{*} P<$ 0.05 versus control WT; ${ }^{*} P<0.05$ versus colitic WT. 

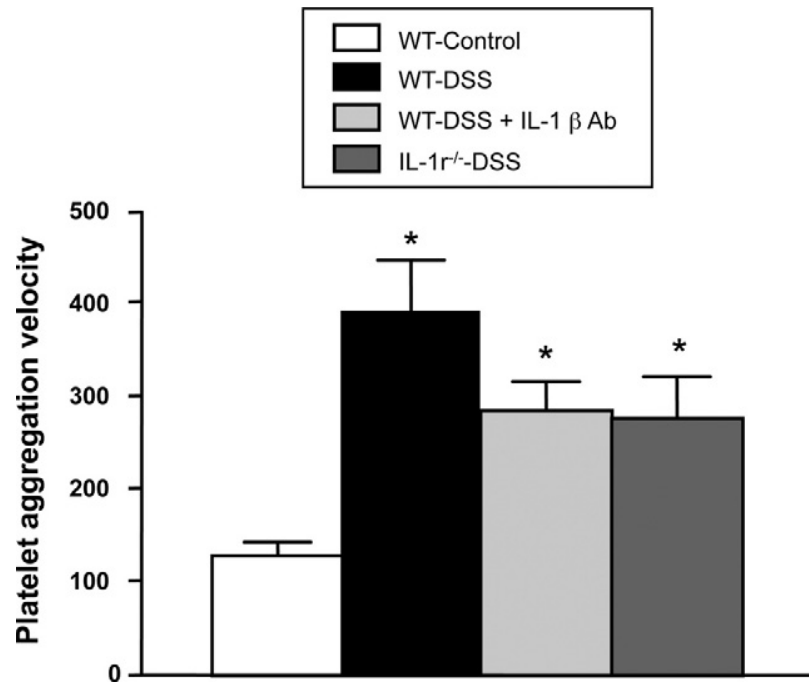

Figure 7. The velocity of aggregation (to thrombin, $0.63 \mathrm{U} / \mathrm{ml}$ ) of platelets from WT-control $(n=6)$, WT-DSS $\left(n=6 ;{ }^{*} P<0.01\right.$ versus WT), WT-DSS + IL- $1 \beta$ antibody $\left(n=5 ; P<0.05\right.$ versus WT), and IL- $1 \mathrm{r}^{-1-}$-DSS $(n=5 ; P<$ 0.05 versus WT mice)

by IL-1r deficiency was comparable with that noted in colitic WT mice treated with the IL-1 $\beta$ antibody (Figure 5).

In another series of experiments, we compared the thrombotic responses to light/dye injury following DSS treatment between WT $(n=4)$ and MyD88 ${ }^{-1-}(n=7)$ mice. This analysis revealed no significant differences in either the time of onset (WT $=2.0 \pm 0.5$ minutes versus MyD88 $^{-l-}=3.7 \pm 0.7$ minutes, $P=0.10$ ) or the time to flow cessation (WT $=15.4 \pm 1.6$ minutes, MyD88 ${ }^{-1-}=$ $15.2 \pm 0.6$ minutes, $P=0.94$ ) between the two groups of colitic mice, suggesting that MyD88 signaling does not contribute to the DSS-induced, IL-1 $\beta$ mediated arteriolar thrombosis.

Figure 7 compares the aggregation responses to thrombin in platelets derived from control and DSS colitic mice. A significantly $(P<0.01)$ enhanced (threefold increase in velocity) aggregation response was noted in WT-DSS mice compared with controls, suggesting an increased sensitivity to thrombin. The accelerated aggregation responses were also noted in platelets derived from WT-DSS mice treated with the IL-1 $\beta$ blocking antibody, and in platelets from IL-1 ${ }^{-1-}$-DSS mice $(P<0.05$ versus WT-Control). The latter responses were not significantly different from the aggregation velocity noted with platelets from WT-DSS mice.

\section{Discussion}

IBD is associated with an increased risk of extra-intestinal thrombosis. Altered coagulation/anticoagulant pathways and activated platelets appear to underlie this pathophysiological response to gut inflammation. ${ }^{1,21}$ The coagulation abnormalities and enhanced thrombosis are also manifested in animal models of colonic inflammation. Although these animal studies have revealed contributions of tissue factor, activated protein $\mathrm{C}$, and thrombin in the colitis-induced enhancement of microvascular throm- bosis, ${ }^{3,6,7}$ the circulating factors and/or cells that enable gut inflammation to exert a distant effect on thrombus formation in other tissues remain poorly understood. The results of the present study support a role for the cytokine $\mathrm{IL}-1 \beta$ as a mediator of the enhanced extra-intestinal thrombosis associated with gut inflammation.

$\mathrm{IL}-1 \beta$ is a pro-inflammatory cytokine that is produced by macrophages, monocytes, and dendritic cells. When the cytokine engages with its receptor (IL-1r) on endothelial cells, there is an increased expression of adhesion molecules that promote the adhesion and transmigration of leukocytes. ${ }^{22-24}$ Elevated levels of $\mathrm{IL}-1 \beta$ in inflamed gut tissue and plasma has been reported for patients with IBD. ${ }^{25,26}$ Although animal models of IBD have generally yielded elevated tissue levels of the cytokine, ${ }^{27,28}$ plasma IL-1 $\beta$ concentration has been reported not to change. ${ }^{26,29}$ In the present study, a large increase in colonic IL-1 $\beta$ concentration was detected in DSS-treated mice, whereas plasma IL-1 $\beta$ was not significantly altered. However, a large and significant increase in IL-1 $\beta$ concentration was detected in distant skeletal muscle tissue in DSS colitic mice, when compared with control mice. Our observation that venules in cremaster muscle of colitic mice exhibit an increased recruitment of rolling and firmly adherent leukocytes (Figure 2) is consistent with an extra-intestinal inflammatory response that may be mediated by IL-1 $\beta$ and/or other cytokines produced within skeletal muscle. It remains unclear how DSS colitis leads to increased $\mathrm{IL}-1 \beta$ levels in skeletal muscle despite an unchanged plasma concentration of the cytokine. It is possible that other factors circulating in blood of the colitic mice stimulate macrophages residing in distant tissues to produce IL-1 $\beta$. Alternatively, circulating leukocytes that are activated during passage through the vasculature of the inflamed gut may be sequestered in distant tissues like skeletal muscle, where they can produce $\mathrm{IL}-1 \beta$ and possibly other cytokines. Additional work is needed to define the source of the elevated $I L-1 \beta$ in skeletal muscle of mice with DSS colitis.

Our results provide several lines of evidence that implicates IL-1 $\beta$ as a mediator of the enhanced extra-intestinal thrombosis response to light/dye injury in colitic mice: (1) exogenous IL-1 $\beta$, administered locally by intrascrotal injection into control mice, elicits a significant reduction in both the time of onset of thrombosis (a measure of the initiation phase of thrombosis) and the time to flow cessation (a measure of the propagation and stabilization phases of thrombosis); (2) treatment of DSS colitic mice with an IL-1 $\beta$ blocking antibody diminishes the enhanced prothrombotic response to light/dye injury; and

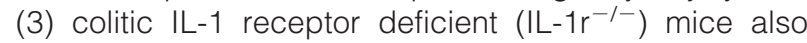
exhibit an attenuated thrombosis response. The magnitude of the responses noted in these experiments (Figures 5 and 6 ) indicates that endogenous IL-1 $\beta$ could account for nearly half of the accelerated thrombus formation associated with experimental colitis. Although the factor(s) that account for the remainder of the thrombosis response remains unclear, a role for other cytokines cannot be ruled out.

Studies of the altered coagulation and microvascular thrombosis that accompanies sepsis have revealed that 
cytokines like IL-1 $\beta$ are powerful inducers of coagulation. ${ }^{30}$ The protein $\mathrm{C}$ pathway appears to be especially sensitive to down-regulation by IL-1 $\beta$. Thrombomodulin and the transcription of endothelial cell protein $C$ receptor gene are inhibited by $\mathrm{IL}-1 \beta$, which would limit protein $\mathrm{C}$ activation and promote thrombus formation. The cytokine is also known to elicit the shedding of endothelial cell protein $\mathrm{C}$ receptor thereby producing circulating soluble endothelial cell protein $C$ receptor that can inhibit protein $\mathrm{C}$ activation. ${ }^{31} \mathrm{IL}-1 \beta$ can also induce the expression of tissue factor on endothelial cells ${ }^{32}$ and monocytes, ${ }^{30}$ and it has been shown to promote platelet-endothelial cell adhesion. ${ }^{33}$ Since tissue factor mediates the initiation phase of thrombosis, whereas thrombin generation resulting from protein $\mathrm{C}$ pathway inhibition would mediate the propagation/stabilization phases, the known actions of IL-1 $\beta$ on the coagulant pathway appear to be consistent with our observation that the cytokine contributes to both the accelerated initiation and propagation/stabilization phases of thrombosis that accompanies experimental IBD.

The transcription-dependent production of other cytokines by IL- $1 \beta$ has received attention in other models of coagulation/thrombosis. ${ }^{9-11}$ However, our results in MyD88 $^{-1-}$ mice suggest that transcription-dependent production of more potent prothrombotic cytokines (eg, IL-6) via MyD88 signaling is an unlikely explanation for our findings. Studies in neuronal tissue have revealed that IL-1 receptor activation can elicit responses that are both MyD88-dependent and -independent. ${ }^{34}$ The MyD88 adaptor molecule has been previously implicated in a different model (1.2\% DSS) of murine colitis, wherein MyD88 deficiency resulted in a more severe form of colonic inflammation. ${ }^{35}$ These findings were interpreted to reflect a critical role for MyD88 signaling in mediating the protective role of the innate immune system in the gut against the development of colitis. Whether such an action on the innate immune system counteracted any potential beneficial effect of MyD88 deficiency on the thrombotic response remains unclear. Furthermore, as discussed above, the thrombosis mediated by IL-1 $\beta$ may relate more to the ability of the cytokine to downregulate components of the protein $\mathrm{C}$ pathway, than through transcription-dependent up-regulation of prothrombotic factors.

A novel and potentially important finding in this study was the enhanced sensitivity of platelets from DSS colitic mice to aggregation induced by thrombin. This is consistent with reports describing an enhanced sensitivity of platelets from patients with IBD to thrombin and other agonists. ${ }^{36,37}$ Our finding that the DSS-induced enhancement of platelet aggregation was also observed in IL$1 \mathrm{r}^{-1-}$ mice and in WT mice treated with an IL-1 $\beta$ blocking antibody suggests that the cytokine is more likely to promote thrombosis by acting on the vessel wall, rather than exerting a direct effect on platelets.

In conclusion, the results of this study indicate that $\mathrm{IL}-1 \beta$ is an important mediator of the enhanced microvascular thrombosis that occurs in extraintestinal tissue during colonic inflammation. Our findings raise the possibility that this cytokine contributes to the hypercoagula- ble state that accompanies IBD and suggest that cytokines may be a relevant therapeutic target for the prevention of thromboembolic events in patients with IBD.

\section{References}

1. Vrij AA, Rijken J, van Wersch JW, Stockbrügger RW: Coagulation and fibrinolysis in inflammatory bowel disease and in giant cell arteritis. Pathophysiol Haemost Thromb 2003, 33:75-83

2. van Bodegraven AA, Schoorl M, Linskens RK, Bartels PC, Tuynman $\mathrm{HA}$ : Persistent activation of coagulation and fibrinolysis after treatment of active ulcerative colitis. Eur J Gastroenterol Hepatol 2002, $14: 413-418$

3. Anthoni C, Russell J, Wood KC, Stokes KY, Vowinkel T, Kirchhofer D Granger DN: Tissue factor: a mediator of inflammatory cell recruitment, tissue injury, and thrombus formation in experimental colitis. J Exp Med 2007, 204:1595-1601

4. Scaldaferri F, Sans M, Vetrano S, Graziani C, De Cristofaro R, Gerlitz B, Repici A, Arena V, Malesci A, Panes J, Grinnell BW, Danese S: Crucial role of the protein $C$ pathway in governing microvascular inflammation in inflammatory bowel disease. J Clin Invest 2007, 117:1951-1960

5. Onomura M, Tsukada $H$, Fukuda K, Kodama M, Nakamura $H$, Hosokawa M, Ohya M, Seino Y: Effect of argatroban on trinitrobenzene sulfonic acid-induced colitis. J Gastroenterol Hepatol 2000, 15:931-938

6. Yoshida H, Russell J, Stokes KY, Yilmaz CE, Esmon CT, Granger DN Role of the protein $\mathrm{C}$ pathway in the extraintestinal thrombosis associated with murine colitis. Gastroenterology 2008, 135:882-888

7. Yoshida H, Russell J, Granger DN: Thrombin mediates the extraintestinal thrombosis associated with experimental colitis. Am J Physiol Gastrointest Liver Physiol 2008, 295:G904-G908

8. Raddatz D, Toth S, Schwörer H, Ramadori G: Glucocorticoid receptor signaling in the intestinal epithelial cell lines IEC-6 and Caco-2: evidence of inhibition by interleukin-1beta. Int J Colorectal Dis 2001, 16:377-383

9. Witowski J, Tayama H, Ksiazek K, Wanic-Kossowska M, Bender TO, Jörres A: Human peritoneal fibroblasts are a potent source of neutrophil-targeting cytokines: a key role of IL-1beta stimulation. Lab Invest 2009, 89:414-424

10. Kwon KH, Murakami A, Hayashi R, Ohigashi H: Interleukin-1beta targets interleukin-6 in progressing dextran sulfate sodium-induced experimental colitis. Biochem Biophys Res Commun 2005, 337:647-654

11. Medzhitov R, Preston-Hurlburt P, Kopp E, Stadlen A, Chen C, Ghosh $\mathrm{S}$, Janeway CA: MyD88 is an adaptor protein in the $\mathrm{hToll} / \mathrm{IL}-1$ receptor family signaling pathways. Mol Cell 1998, 2:253-258

12. van der Poll T, van Deventer SJ: Cytokines and anticytokines in the pathogenesis of sepsis. Infect Dis Clin North Am 1999, 13:413-426

13. Vowinkel T, Kalogeris TJ, Mori M, Krieglstein CF, Granger DN: Impact of dextran sulfate sodium load on the severity of inflammation in experimental colitis. Dig Dis Sci 2004, 49:556-564

14. Ostanin DV, Bao J, Koboziev I, Gray L, Robinson-Jackson SA, Kosloski-Davidson M, Price VH, Grisham MB: T cell transfer model of chronic colitis: concepts, considerations, and tricks of the trade. Am J Physiol Gastrointest Liver Physiol 2009, 296:G135-G146

15. Hickey MJ, Kanwar S, McCafferty DM, Granger DN, Eppihimer MJ, Kubes P: Varying roles of E-selectin and P-selectin in different microvascular beds in response to antigen. J Immunol 1999, 162:1137-1143

16. Vowinkel T, Wood KC, Stokes KY, Russell J, Tailor A, Anthoni C, Senninger N, Krieglstein CF, Granger DN: Mechanisms of platelet and leukocyte recruitment in experimental colitis. Am J Physiol Gastrointest Liver Physiol 2007, 293:G1054-G1060

17. Ishikawa M, Sekizuka E, Yamaguchi N, Nakadate H, Terao S, Granger $\mathrm{DN}$, Minamitani $\mathrm{H}$ : Angiotensin II type 1 receptor signaling contributes to platelet-leukocyte-endothelial cell interactions in the cerebral microvasculature. Am J Physiol Heart Circ Physiol 2007, 292:H2306-H2315

18. Rumbaut RE, Randhawa JK, Smith CW, Burns AR: Mouse cremaster venules are predisposed to light/dye-induced thrombosis indepen- 
dent of wall shear rate, CD18, ICAM-1, or P-selectin. Microcirculation 2004, 11:239-247

19. Rumbaut RE, Slaff DW, Burns AR: Microvascular thrombosis models in venules and arterioles in vivo. Microcirculation 2005, 12:259-274

20. Mindukshev IV, Jahatspanian IE, Goncharov NV, Jenkins RO, Krivchenko Al: A new method for studying platelets, based upon the low-angle light scattering technique. 1. Theoretical and experimental foundations of the method. Spectroscopy 2005, 19:235-246

21. Harries AD, Beeching NJ, Rogerson SJ, Nye FJ: The platelet count as a simple measure to distinguish inflammatory bowel disease from infective diarrhea. J Infect 1991, 22:247-250

22. Sikorski EE, Hallmann R, Berg EL, Butcher EC: The Peyer's patch high endothelial receptor for lymphocytes, the mucosal vascular addressin, is induced on a murine endothelial cell line by tumor necrosis factor-alpha and IL-1. J Immunol 1993, 151:5239-5250

23. Luscinskas FW, Brock AF, Arnaout MA, Gimbrone MA Jr: Endothelialleukocyte adhesion molecule-1-dependent and leukocyte (CD11/ CD18)-dependent mechanisms contribute to polymorphonuclear leukocyte adhesion to cytokine-activated human vascular endothelium. J Immunol 1989, 142:2257-2263

24. Wang S, Dangerfield JP, Young RE, Nourshargh S: PECAM-1, alpha6 integrins and neutrophil elastase cooperate in mediating neutrophil transmigration. J Cell Sci 2005, 118:2067-2076

25. Gionchetti P, Campieri M, Belluzzi A, Tampieri M, Bertinelli E, Brignola C, Ferretti M, Boni P, lannone P, Miglioli M, et al: Interleukin 1 beta (IL-1 beta) release from fresh and cultured colonic mucosa in patients with ulcerative colitis (UC). Agents Actions 1992, Spec No:C50-C52

26. Ruffolo C, Scarpa M, Faggian D, Pozza A, Navaglia F, D'Incà R, Hoxha P, Romanato G, Polese L, Sturniolo GC, Plebani M, D'Amico DF, Angriman I: Cytokine network in rectal mucosa in perianal Crohn's disease: relations with inflammatory parameters and need for surgery. Inflamm Bowel Dis 2008, 14:1406-1412

27. You Y, Fu JJ, Meng J, Huang GD, Liu YH: Effect of N-acetylcysteine on the murine model of colitis induced by dextran sodium sulfate through up-regulating PON1 activity. Dig Dis Sci 2009, 54:1643-1650

28. Melgar S, Karlsson A, Michaëlsson E: Acute colitis induced by dex- tran sulfate sodium progresses to chronicity in C57BL/6 but not in BALB/c mice: correlation between symptoms and inflammation. Am J Physiol Gastrointest Liver Physiol 2005, 288:G1328-G1338

29. Alex P, Zachos NC, Nguyen T, Gonzales L, Chen TE, Conklin LS, Centola M, Li X: Distinct cytokine patterns identified from multiplex profiles of murine DSS and TNBS-induced colitis. Inflamm Bowel Dis 2009, 15:341-352

30. Mattsson E, Herwald H, Egesten A: Superantigens from Staphylococcus aureus induce procoagulant activity and monocyte tissue factor expression in whole blood and mononuclear cells via IL-1 beta. J Thromb Haemost 2003, 1:2569-2576

31. Qu D, Wang Y, Esmon NL, Esmon CT: Regulated endothelial protein $C$ receptor shedding is mediated by tumor necrosis factor-alpha converting enzyme/ADAM17. J Thromb Haemost 2007, 5:395-402

32. Hahn CL, Best AM, Tew JG: Rapid tissue factor induction by oral streptococci and monocyte-IL-1beta. J Dent Res 2007, 86:255-259

33. Danese S, Katz JA, Saibeni S, Papa A, Gasbarrini A, Vecchi M, Fiocchi C: Activated platelets are the source of elevated levels of soluble CD40 ligand in the circulation of inflammatory bowel disease patients. Gut 2003, 52:1435-1441

34. Davis CN, Mann E, Behrens MM, Gaidarova S, Rebek M, Rebek J, Bartfai T: MyD88-dependent and -independent signaling by IL-1 in neurons probed by bifunctional Toll/L-1 receptor domain/BB-loop mimetics. Proc Natl Acad Sci 2006, 103:2953-2958

35. Araki A, Takanori K, Takahiro I, Makita S, Urashhara K, liyam R, Totsuka T, Takeda K, Akira S, Watanabe M: MyD88-deficient mice develop severe intestinal inflammation in dextran sodium sulfate colitis. J Gastroenterol 2005, 40:16-23

36. Andoh A, Yoshida T, Yagi Y, Bamba S, Hata K, Tsujikawa T, Kitoh K, Sasaki M, Fujiyama Y: Increased aggregation response of platelets in patients with inflammatory bowel disease. J Gastroenterol 2006 , 41:47-54

37. Yoshida H, Granger DN: Inflammatory bowel disease: a paradigm for the link between coagulation and inflammation. Inflamm Bowel Dis 2009, 15:1245-1255 